\title{
Türkiye'de Mevduat Banka Kredisi Ve Ekonomik Büyüme İlişkisinin İncelenmesi*
}

\author{
N.Serap VURUR** \\ Ercan ÖZEN***
}

\section{Özet}

Bu çalışmanın amacı, Türkiye'de mevduat, banka kredileri ve ekonomik büyüme arasındaki karşılıklı etkileşimi araştırmaktır. Çalışmada 1998:1- 2012:1 dönemine ait üçer aylık veriler kullanılmıştır. Kredi, mevduat ve ekonomik büyüme arasındaki nedensellik ilişkisi Granger Nedensellik Testi ile araştırılmıştır.

Çalışmadan elde edilen bulgular, mevduatlardan hem ekonomik büyümeye hem de kredilere doğru, ekonomik büyümeden ise kredilere doğru bir nedensellik ilişkisinin olduğunu göstermiştir. Ekonomide mevduat hacminde yaşanan büyümenin hem ekonomik büyümeyi hem de kredi hacmini artırdığı söylenebilir. Ayrıca ekonomik büyümeye bağlı olarak firmaların ve bireylerin artan yatırım ve finansman ihtiyacı nedeniyle kredi hacminde artış yaşandığı da düşünülebilir.

Anahtar Kelimeler: Mevduat, Kredi, Ekonomik Büyüme, Granger Nedensellik Testi, Türk Bankacılık Sistemi

\section{The Examination Of The Relationship Between Deposits Bank Credits And Economic Growth In Turkey}

\begin{abstract}
The aim of this study is to investigate the relationship between bank deposits, bank credit and economic growth in Turkey. In this study, quarterly monthly data from 1998:1 to 2012:1 periods have been used and Granger Causality Test has been applied to investigate the direction of causality between deposits, credit and economic growth.

\footnotetext{
*Bu makale revize edilmeden önce, Erzurum'da düzenlenen 16. Finans Sempozyumunda “Türkiye'de Tasarruf, Banka Kredisi ve Büyüme İlişkisi (19982012)" başlı̆̆ altında bildiri olarak sunulmuştur.

** Yrd. Doç. Dr., Afyon Kocatepe Üniversitesi Bolvadin UBYO. Muhasebe Bölümü serapvurur@aku.edu.tr

*** Yrd. Doç. Dr., Uşak Üniversitesi- UBYO. Bankacıllk ve Finans Bölümü ercan.ozen@usak.edu.tr
} 
According to the findings; there are unidirectional causality from deposits to economic growth, from economic growth to credit and from deposits to credits. But, any causality for opposite hasn't been found. It can be said that increase in deposit volume leads to both economic growth and credit volume. Besides, due to increase in investment and financial needs of both firms and individuals, an increase is also thought to occur in loan volume depending on economic growth.

Keywords: Bank Deposits, Credit, Economic Growth, Granger Causality Test, Turkish Banking System

\section{Giriş}

Ekonomik olarak büyümenin sağlanması kalkınmakta olan ülkeler için hayati bir önem taşımaktadır. Günümüz dünyasında yaşanan hızlı teknolojik gelişmeler sonucu; iletişim ağlarının piyasalara ulaşım imkanlarını neredeyse sınırsız hale getirmesi, finansal piyasaların sürekli gelişme içinde olmasına yol açmıştır. Finansal sistem, kalkınma için gerekli olan fonlar ve tasarrufların toplanmasını sağlayarak pek çok yatırım projesinin hayata geçirilmesine imkan vermektedir. Finansal sistemin dışında kalan kişi ve kurumların sisteme kazandırılmasıyla ülkedeki tasarruf miktarı artmakta, artan tasarruflar sermaye birikimini destekleyerek, kredi mekanizması yoluyla ekonomik büyüme ve istihdam yaratılmasını sağlamaktadır.

2012 yılında Dünya Bankası tarafından yayınlanan "Yüksek Büyümenin Sürdürülebilirliği: Yurtiçi Tasarrufların Rolü, Türkiye Ülke Ekonomik Raporu" nda (Rapor No: 66301-TR) Türkiye'de tasarrufların milli gelire oranının düşme eğiliminde olduğu vurgulanmaktadır. Bu düşüşün ekonomik büyüme üzerinde olumsuz etkisinin olması muhtemeldir.

Finansal sistemin büyüklüğü, kredi hacmi ve bunun kredilere yansıyarak ekonomik gelişmeyi sağlayıp sağlamadığı çok fazla ilgi gören konulardandır. Bu çalışmada, sözü edilen ilişkiler mevduat değişkeni tek başına kullanılarak ortaya konulmak istenmiştir.

$\mathrm{Bu}$ çalışmanın temel amacı; mevduat ile kredi, kredi ile ekonomik büyüme ve mevduat ile ekonomik büyüme arasındaki nedensellik ilişkisini araştırmaktır.

Çalışma 1998:1-2012:1 dönemini kapsamaktadır. Türkiye'de kredilerin ve mevduat ekonomik büyüme üzerindeki etkisi VAR modeli üzerinden Granger Nedensellik Testi ile araştırılmıştır. 


\section{Mevduat Kredi ve Ekonomik Büyüme İlişsisi}

Finansal araçlar, piyasalar, aracı kurumlar, fon arz ve talep edenler, hukuki ve idari yapıdan oluşan finansal sistemin tasarruf oranları, yatırım kararları ve teknolojik yenilikleri etkilemek yoluyla ekonomik büyüme oranlarını etkileyebileceği oldukça tartışılan bir konudur. Finansal sistemin ekonomik büyüme üzerine etkili olup olmadığ bulunmaktadır. Finansal sistemin ekonomik büyüme üzerinde etkili olduğunu savunanlar; (Rajan ve Luigi (1998), Keskin ve Karşıyakalı, (2006) ile Alper ve Öniş (2001) gelişmiş bir finansal sistemle ekonomideki kaynakların daha verimli alanlarda kullanılmasıyla, ekonomideki üretkenliğin artacağını, sermaye birikimi oluşturulacağını, bunun da ekonomik büyümeyi hızlandıracağını söylemektedir. Öte yandan finansal sistemin ekonomik büyümeyi etkilemeyeceğini savunan görüşler de mevcuttur(Al Yousif, (2002), Levine (1997). Bu görüşlere göre ise finansal sistemdeki tekelci yapı, düzenlemelerdeki yetersizlikler ve sisteme giren fon kaynaklarının verimli yatırımlara aktarımının sağlanamaması ekonomik büyümeyi olumsuz etkilemektedir. Aynı zamanda finansal piyasalarda etkileşimin artması sonucu oluşabilen ani sermaye hareketleri ve sistemdeki kırılganlıklar ekonomik büyümeyi olumsuz etkileyebilmektedir.

Finansal gelişme ile ekonomik büyüme arasındaki ilişkiyi açıklayan neo-klasik ve içsel büyüme teorileri finansal gelişmenin ekonomik gelişmeyi farklı açılardan etkilediğini belirtmektedir. Neo klasik teoride finansal gelişme yüksek etkinlik, yüksek tasarruf ve yatırım sağlayarak ekonomik büyümeyi geçici olarak teşvik etmektedir. İçsel büyüme teorisinde ise, finansal gelişme tasarrufları etkileyerek uzun dönemde ekonomik büyümeye neden olmaktadır (Şentürk, 2005:126).

Diğer taraftan; bazı araştırmacılar finansal gelişmenin ekonomik büyümenin belirleyicisi olduğu görüşünde (arz-öncü hipotezi) iken, bazıları da finansal gelişmenin ekonomik büyümenin sonucu olduğunu (talepizleyici hipotezi) söylemektedirler. (Müslümov ve Aras: 2005). Arz öncü hipotezine göre, önce finansal piyasalarda gelişme olmakta, bu da ekonomik büyümeyi tetiklemektedir. Talep izleyici hipotezine göre ise, ekonomik büyüme sonucu finansal ürünlere olan talep artmakta, bu da finansal büyüme sonucunu doğurmaktadır.

\section{Literatür İncelemesi}

Literatürde ekonomik büyüme ve finansal gelişmişlik ilişkisinin incelemesi boyutunda çok sayıda çalışma yer almaktadır. Rajan ve Zingales, 1998, Demirguç-Kunt ve Maksowic 1998, Beck, Levine, Demirgüç-Kunt ve 
Loaven 2008, Levine 2005' in çalışmalarında finansal gelişmişlikle ekonomik büyüme arasında güçlü bir nedensellik ilişkisi tespit edilmiştir. Rajan\&Zingales (1998) gelişmiş finansal piyasalardaki firmaların finansman kaynağına kolay ulaşabilmelerinin finansman maliyetlerini azalttığını, bu durumun 1980'lerde pek çok ülkede örneğinin görülebileceğini söylemektedir. Demirgüç-Kunt ve Maksowic (1998) ise hukuki ve finansal yapılardaki farklılıkların firmalara etkisini araştırmış, büyük olmasa da finansal sistemde yer alan bankacilık sektörünün firmaların büyümesiyle ilişkili olduğunu ortaya koymuştur. Levine (2005) finansal gelişme ve büyüme arasındaki teorik yaklaşımları incelemiş, gelişmiş bir finansal sistemin firmaların karşı karşıya kaldığı finansman kısıtları mekanizmasını ortadan kaldırarak ekonomik büyümeyi sağladığı sonucuna ulaşmıştır. Beck, Levine, Demirgüç-Kunt, Leoven (2008) de yaptıkları çalışma ile Levine'in (2005) ertaya koyduğu finansal gelişmeye ilişkin teorik çerçeveyi geliştirmeyi hedeflemişler ve çalışmalarında finansal gelişmenin özellikle gelişmede lokomotif kabul edilen küçük işletmelerde daha büyük bir gelişme sağladığını belirtmişler, aynı zamanda finansal gelişimin gelir eşitsizliğini azalttığını göstermiş̧lerdir.

Arestis, Demetriades ve Luintel (2001), çalışmalarında ekonomik büyüme üzerinde bankacilık sektöründeki gelişiminin hisse senedi piyasasındaki gelişime oranla daha büyük bir etkiye sahip olduğuna dair bulgulara ulaşmışlardır. Xu (2000), 41 ülkeyi içeren çalışmasında VAR yaklaşımını kullanmış ve 1960-1993 döneminde finansal gelişmenin ekonomik büyüme üzerindeki etkilerini incelemiştir. Sonuç olarak finansal büyümenin ekonomik gelişmeyi izlemediğini tespit etmiştir.

Chang vd.( 2010), banka fonları ve ekonomik büyüme arasındaki ilişkiyi Çin örneğinde incelemişler ve banka mevduatlarıyla büyüme arasında pozitif bir ilişki olduğunu ortaya koymuşlardır.

Lu ve Shen (2012), tarafından Çin'de yapılan bir çalışmada yabanc1, şehir ve diğer bankalar olarak ayırdıkları bankalardan verilen kredilerin Çin şehirlerinin ekonomik büyümesi üzerine etkisini araştırmışlardır. Yabancı bankaların verdikleri kredilerin ekonomik büyüme üzerinde pozitif ve güçlü bir etkiye sahip olduğu tespit edilmiştir.

Islam ve Shah (2012), Malezya'daki bankacılık dışı finansal aracılık hizmeti veren kurumlarla ekonomik büyüme arasındaki nedensellik ilişkisi üzerine 1974-2004 dönemi için sınır testi (ARDL) kullanarak çalışma yapmışlardır. Yaptıkları çalışmada bankacılık dışı finansal aracılık hizmeti 
veren kurumlarla ekonomik büyüme arasında uzun dönemli bir ilişkinin varlığı ortaya konmuştur.

Müslümov ve Aras (2002)'ın Ekonomik İşbirliği ve Kalkınma Örgütü (OECD) üyesi 22 ülkenin 1982-2000 dönemi verileri ile yaptıkları çalışma, sermaye piyasalarının gelişmesinin ekonomik büyümenin Granger nedeni olduğunu göstermektedir.

Türkiye'de finansal büyüme ve ekonomik büyüme ilişkisi farklı yöntemlerle çalışılmıştır. Kar ve Pentecost (2000), finansal gelişme ve ekonomik büyüme arasındaki nedensellik ilişkisini Türkiye özelinde incelemiştir. Çalışmalarında para arzının milli gelire oranı, banka mevduatlarının milli gelire oranı, özel sektöre kullandırılan kredilerin milli gelire oranı, yurt içi krediler içinde özel sektör kredilerinin oranı, yurt içi kredilerin milli gelire oranı değişkenlerini kullanmışlar ve değişkenlere göre farklı sonuçlara ulaşmışlardır. Para arzının milli gelire oranı ve yurtiçi kredilerin milli gelire oranı değişkenleriyle ekonomik büyüme arasındaki nedensellik ilişkisinin varlığı sonucuna ulaşılırken, banka mevduatlarının milli gelire oranı, yurtiçi kredilerin milli gelire oranı ve yurtiçi kredilerin özel sektör kredilerine oranı değişkenlerinin ekonomik büyüme arasında nedensellik ilişkisinin olmadığı sonucuna ulaşılmıştır. Soytaş ve Küçükkaya da (2011), altı farklı finansal gelişme değişkeni kullanarak yaptıkları çalışmalarında; finansal gelişme ile ekonomik büyüme arasında nedensellik ilişkisi bulamamışlardır. Ancak, Mercan ve Peker (2013), 1992-2010 dönemi verilerini kullanarak, Türkiye'de finansal gelişmenin kısa ve uzun dönemde ekonomik büyüme üzerinde anlamlı ve pozitif etkiye sahip olduğunu bulmuşlardır.

Aslan ve Küçükaksoy (2006), Türkiye'de finansal gelişme ve ekonomik büyüme ilişkisini 1970-2004 dönemine ait verilerle Granger Nedensellik Testiyle incelemiş ve finansal gelişmenin ekonomik büyümeyi arttırdığı sonucuna ulaşmışlardır. Altıntaş ve Ayrıçay (2010), 1987-2007 yıllarına ilişkin verileri Pesaran (2001) tarafından geliştirilen sınır testi yaklaşımı (ARDL) ile analiz ederek reel büyüme, finansal gelişme, dışa açıklık ve reel faiz oranı arasında uzun dönemde eş bütünleşme ilişkisinin olduğunu bulmuşlardır.

Demirhan vd. (2011) Türkiye de finansal gelişme ile ekonomik büyüme arasındaki nedensellik ilişkisini özel sektöre verilen banka kredileri ve gayri safi yurtiçi hasıla değişkenlerine ilişkin 1987:1-2006:4 yıllarına ait veriler yardımıyla, Vector Error Correction Modelini (VECM) kullanarak 
incelemişler ve değişkenler arasında iki yönlü bir nedensellik ilişkisi tespit etmişlerdir.

Öztürk vd. (2011), finansal gelişme ve ekonomik büyüme ilişkisini, panel nedensellik testi ile 1992-2009 dönemi verileriyle dokuz ülke için incelenmişler ve ekonomik gelişmeden finansal büyümeye doğru bir nedensellik ilişkisi bulmuşlardır.

Artan (2007), finansal gelişmenin ekonomik büyüme üzerindeki etkisinin ülkelerin gelir düzeyi ile ilgili olduğunu öne sürmektedir. Yazar; düşük, orta ve yüksek gelire sahip 79 ülke için 1980-2002 dönemini ele aldığı çalışmasında, orta ve yüksek gelirli ülkelerde finansal büyüme ile ekonomik büyüme arasında pozitif bir ilişki bulurken, düşük gelirli ülkelerde ise finansal büyümenin ekonomik gelişmeyi negatif olarak etkilediğini bulmuştur. Şentürk (2005), yapmış olduğu literatür çalışmasında, kısa dönemde finansal gelişmenin ekonomik büyümeyi arttırdığını, uzun dönemde ise nedensellik ilişkisinin iki yönlü olduğunu ortaya koymuştur.

Y1lmaz ve Kaya (2006), M2/GSYİH, Mevduat/GSYİH, Sektörel Krediler/GSYIH ve Finansal Tasarruflar/GSYİH oranlarını kullandıkları çalışmada finansal gelişme ile ekonomik büyüme arasında uzun dönemli bir ilişki olmadığını, ekonomik büyümeden finansal büyümeye doğru tek yönlü bir nedensellik ilişkisi olduğunu belirlemişlerdir. Buna göre ekonomik büyüme ve finansal büyüme arasındaki ilişki "talep takibi" biçimindedir.

Türkiye'de kredi kullanımı ekonomik büyüme ilişkisini inceleyen ilk çalışmalardan birisi Güven (2002) tarafından yapılmıştır. Güven, 1988-2001 dönemi için kredi değişkeni için üçer aylık banka kredilerindeki reel yüzde değişim ve büyüme değişkeni için ise reel GSMH'daki yüzdesel değişim verilerini kullanarak Granger nedenselliği, varyans ayrıştırması ve regresyon analizi gibi ekonometrik yöntemleri uygulamıştır. Çalışmada krediler ile ekonomik büyüme arasında Granger nedensellik ilişkisine ulaşılmamıştır. Ancak, varyans ayrıştırması ve regresyon sonuçları krediler ile ekonomik büyüme arasında pozitif yönlü ilişki olduğunu ortaya koymuştur.

Ceylan ve Durkaya (2010), 1998-2008 dönemi yurtiçi kredi hacmi ve ekonomik büyüme içeren serilere Granger nedensellik testi uygulamışlar ve ekonomik büyümeden kredilere doğru tek yönlü bir nedensellik ilişkisi bulmuşlardır. Banka kredileri ve ekonomik büyüme ilişkisine yönelik çalışmalardan bir diğeri de Dişbudak (2010) tarafından 1961-2008 yıllarına ilişkin veriler kullanılarak yapılmıştır. ARDL sınır testinin kullanıldığı 
çalışmada banka kredilerinin ekonomik büyümeye pozitif yönde etki yaptığı tespit edilmiştir.

Literatürde özellikle finansal sistem büyüklüğü ile ekonomik büyüme arasındaki ilişkiyi araştıran çok sayıda çalışma bulunmaktadır. Kredi ekonomik büyüme ilişkisine ilişkin görece daha az çalışmaya rastlanmakta iken, banka mevduat hacmi ile kredi hacmi arasında ilişki olup olmadığını araştıran ekonometrik çalışmalara rastlanılmamıştır.

Mevduatların krediye dönüşmesi ülkedeki konjonktürel dalgalanmalar tarafından büyük oranda etkilenebilmektedir. Faiz oranları, ekonomik sistem içinde yer alan oyuncuların ülke istikrarına ilişkin beklentileri, devletin borçlanma gereği, kredi talep edenlerin kullanabileceği fon tutarını etkilemektedir. Ersel ve Tarhan (2001) Türkiye'de mevduatların krediye dönüş oranının kriz dönemlerinde hem faizlerin yükselmesi nedeniyle firmaların kredi talebini kısması, hem de bankaların artan risk nedeniyle firmalara daha az kredi kullandırması nedeniyle düşmekte olduğunu vurgulamıştır. Kamu finansman gereksinimindeki artışlar da, bankaların kredi olarak verebilecekleri fonların tutarını azaltmaktadır.

\section{Araştırma Verileri}

Çalışmada kullanılan tüm veriler, 1998:1-2012:1 dönemine ait üçer aylık reel gayri safi yurtiçi hasıla, bankaların yurtiçinde kullandırmış oldukları toplam kredi ve banka mevduatı bileşenlerinin 12 aylık kümülatif değerlerinden oluşmaktadır. Veri setinin 1998 yılından başlayan değerlerden oluşturulmasının nedeni, istenen formattaki verinin bu tarihten başlayarak elde edilebilmiş olmasıdır.

Çoğu çalışmada M2/GSYİH, Mevduat/GSYİH, Sektörel Krediler/GSYİH ve Finansal tasarruflar/GSYİH gibi veriler finansal büyüme göstergeleri olarak kullanılmıştır. Ancak bu çalışmada; mevduatların kredilerle olan ilişkisini ve bunların da ekonomik büyümeye yansımalarını görmek için mevduat verisi kullanılmıştır. gibidir;

Çalışmada kullanılan değişkenlere ilişkin kısaltmalar aşağıdaki

BYM: Gayrisafi yurtiçi hasıla

KRD: Yurtiçi bankalarca verilen kredi miktarı

MEV: Yurtiçi mevduat verileri. 
Veriler, Türkiye Cumhuriyet Merkez Bankası ve Kalkınma Bakanlığı elektronik veri tabanından elde edilmiş olup serilerin doğal logaritması alınmış ve mevsimsellik etkisinden arındırılmıştır. Verilere ilişkin analizler E-views 5.1 programı kullanılmışır

\section{Metodoloji ve Bulgular}

\section{Birim Kök Testi ve Test Sonuçları}

Büyüme, kredi ve mevduat ilişkisinin incelenmesinde ilk aşama, şokların seriler üzerindeki etkisini ortadan kaldırmak için durağan olup olmadıklarının belirlenmesidir. $\mathrm{Bu}$ aşamada, değişkenlerin durağanlıklarının incelenmesi için Genişletilmiş Dickey Fuller (Augmented Dickey Fuller-ADF) birim kök testi kullanılmıştır Dickey ve Fuller (1981) tarafından geliştirilen ADF testinde kullanılan regresyon denklemi sabitli ve trendli model için aşağıdaki gibi gösterilebilir.

$$
\begin{array}{cc}
\Delta \mathrm{y}_{\mathrm{t}}=\mu+\lambda \mathrm{y}_{\mathrm{t}-1}+\alpha_{\mathrm{i}} \sum_{\mathrm{i}=1}^{\mathrm{k}} \Delta \mathrm{y}_{\mathrm{t}-\mathrm{i}}+\mathrm{u}_{\mathrm{t}} & \text { (Sabit terimli model) } \\
\Delta \mathrm{y}_{\mathrm{t}}=\mu+\beta \mathrm{T}+\lambda \mathrm{y}_{\mathrm{t}-1}+\alpha_{\mathrm{i}} \sum_{\mathrm{i}=1}^{\mathrm{k}} \Delta \mathrm{y}_{\mathrm{t}-\mathrm{i}}+\mathrm{u}_{\mathrm{t}} & \text { (Sabit terimli ve trendli model) } \\
\Delta \mathrm{y}_{\mathrm{t}}=\text { Farkı Alınmış Seri } & \lambda, \beta, \alpha_{\mathrm{i}}=\text { Parametreler } \\
\mu=\text { Sabit Terim } & \mathrm{T}=\text { Trend Faktörü } \\
\mathrm{k}=\text { Gecikme Uzunluğu } & \mathrm{u}_{\mathrm{t}}=\text { Hata Terimi }
\end{array}
$$

Banka kredileri, tasarruflar ve GSYİH arasındaki ilişki incelenmeden önce bu değişkenlere birim kök testi yapılmıştır. Çalı̧̧mada birim kök sınaması genişletilmiş Dickey-Fuller (ADF) testiyle gerçekleştirilmiştir. Çalışmada gecikme sayısı belirlenirken AIC bilgi kriterlerine göre optimal gecikme uzunluğu belirlenmiştir. AIC bilgi kriterlerinin tercih edilmesinin nedeni, modelin en küçük kritik değerini sağlayan gecikme uzunluğunu vermesidir.

Sonuçlar Tablo 1'de gösterilmiştir. 
Uşak Üniversitesi Sosyal Bilimler Dergisi

$2013,6 / 3$

N. S. VURUR, E. ÖZEN

Tablo 1: Geliştirilmiş Dickey Fuller (ADF) Birim Kök Testi Sonuçları

\begin{tabular}{|l|l|}
\hline DEĞİŞKEN & ADF SINAMASI \\
\hline BYM & $-6.498988(0)^{*}$ \\
\hline KRD & $-5,052419(9)^{*}$ \\
\hline MEV & $-6,633641(0)^{*}$ \\
\hline
\end{tabular}

* 0.01 anlamlılık seviyesindedir. Optimum gecikme uzunluğu Akakike Bilgi kriterine (AIC) bilgi kriterine göre hesaplanmış olup parentez içinde gösterilmiştir. Mc Kinnon kritik değerleri; $\% 1$ düzeyinde $-3,552666$, $\%$ 5düzeyinde $-2,914517, \% 10$ düzeyinde $-2,595033$ tür.

ADF birim kök test sonuçlarına göre büyüme, kredi ve mevduat serileri sabitli (kesikli)-trendsiz modelinde hesaplanan test istatistiği, \%1 anlam düzeyinde MacKinnon kritik değerinden mutlak olarak daha büyük olduğundan birim kökün bulunduğuna dair sıfır hipotezi reddedilir. Yani serilerin sabitli (kesikli)-trendsiz modelinde düzey değerinde durağan olduğu ve bütünleşme derecesinin I (0) olduğu görülmektedir.

\section{Granger Nedensellik Testi ve Test Sonuçları}

$\mathrm{Bu}$ çalışmada, Johansen tarafından geliştirilen vektör otoregresif (VAR) modeli kullanılmıştır. Johansen VAR modeli aşağıdaki gibi gösterilebilir.

$$
y_{t}=A_{1} y_{t-1}+\ldots+A_{p} y_{t-p}+B x_{t}+\varepsilon_{t}
$$

$y_{t}$ : Durağan olmayan değişkenler vektörü, $x_{t}$ : deterministik değişkenler vektörü, $\varepsilon_{t}$ : hata terimini göstermektedir.

Değişkenler arasındaki nedensellik ilişkisinin belirlenebilmesinde kullanılan bir analiz yöntemi de Vector (VAR) nedensellik analizidir. Bu nedensellik analizinin uygulanması iki basamakta gerçekleşmektedir. Birinci basamak, sistemdeki değişkenlerin maksimum entegrasyon derecesinin (d) ve gecikme uzunluğunun $(\mathrm{k})$ belirlenmesini içerir. VAR'ın uygun gecikme yapısının belirlenmesi için Akaike'nin minimum Final Prediction Error (FPE), Akaike Information Criterion (AIC), Schwarz Criterion (SC) ve Hannan-Quin (HQ) gibi ölçüler kullanılabilir(Awokuse, 2003).

Bir VAR modeli oluşturmak için gerekli olan değişkenler arasında serilerin sabitli (kesikli)-trendsiz modelinde düzey değerinde durağan olduğu ve bütünleşme derecesinin I (0) olduğu görülmektedir. Bu nedenle kontegrasyon testine gerek duyulmamıştır(Granger,1988). Çalışmamızın bu 
aşamasında, durağan bir yapıya sahip olan gayri safi yurtiçi hasıla, kredi ve mevduat göstergeleri arasındaki nedensellik ilişkisi Granger (1988) nedensellik testi aşağıdaki denklemlerin en küçük kareler yöntemi (EKK) ile tahminine dayanılarak gerçekleştirilmiştir

$$
\begin{aligned}
& K R D_{\mathrm{t}}=\alpha_{1}+\sum_{\mathrm{i}=1}^{\mathrm{n}} \beta_{1 \mathrm{i}} \mathrm{KRD}_{\mathrm{t}-\mathrm{i}}+\sum_{\mathrm{i}=1}^{\mathrm{n}} \gamma_{1 \mathrm{i}} \mathrm{BYM}_{\mathrm{t}-\mathrm{i}}+\mathbf{u}_{1 \mathrm{t}} \\
& B Y M_{\mathrm{t}}=\alpha_{1}+\sum_{\mathrm{i}=1}^{\mathrm{n}} \beta_{1 \mathrm{i}} \mathrm{BYM}_{\mathrm{t}-\mathrm{i}}+\sum_{\mathrm{i}=1}^{\mathrm{n}} \gamma_{1 \mathrm{i}} \mathrm{KRD}_{\mathrm{t}-\mathrm{i}}+\mathrm{u}_{1 \mathrm{t}} \\
& M E V_{\mathrm{t}}=\alpha_{1}+\sum_{\mathrm{i}=1}^{\mathrm{n}} \beta_{1 \overline{\mathrm{i}}} \mathrm{MEV}_{\mathrm{t}-\mathrm{i}}+\sum_{\mathrm{i}=1}^{\mathrm{n}} \gamma_{1 \overline{\mathrm{i}}} \mathrm{BYM}_{\mathrm{t}-\mathrm{i}}+\mathrm{u}_{1 \mathrm{t}} \\
& B Y M_{\mathrm{t}}=\alpha_{1}+\sum_{\mathrm{i}=1}^{\mathrm{n}} \mathrm{\beta}_{1 \mathrm{i}} \mathrm{BYM}_{\mathrm{t}-\mathrm{i}}+\sum_{\mathrm{i}=1}^{\mathrm{n}} \gamma_{1 \mathrm{i}} \mathrm{MEV}_{\mathrm{t}-\mathrm{i}}+\mathrm{u}_{1 \mathrm{t}} \\
& K R D_{\mathrm{t}}=\alpha_{1}+\sum_{\mathrm{i}=1}^{n} \boldsymbol{B}_{1 \overline{\mathrm{i}}} \operatorname{KRD}_{\mathrm{t}-\overline{\mathrm{i}}}+\sum_{\mathrm{i}=1}^{\mathrm{n}} \gamma_{1 \overline{\mathrm{i}}} \mathrm{MEV}_{\mathrm{t}-\mathrm{i}}+\mathbf{u}_{1 \mathrm{t}} \\
& M E V_{t}=\alpha_{1}+\sum_{\mathrm{i}=1}^{\mathrm{n}} \beta_{1 \mathrm{i}} M E V_{t-\bar{i}}+\sum_{\mathrm{i}=1}^{\mathrm{n}} \gamma_{1 \mathrm{i}} K R D_{\mathrm{t}-\mathrm{i}}+\mathrm{u}_{1 \mathrm{t}}
\end{aligned}
$$

VAR'a dayalı olarak yapılan Granger Nedensellik Testinde optimal gecikme uzunluğunu belirlemek için AIC kriteri kullanılmıştır. Optimal gecikme uzunlukları KRD ve BYM değişkenleri ile kurulan model için 13, MEV ve BYM değişkenleri ile kurulan model için 1, KRD ve MEV değişkenleri ile kurulan model için 5 olarak belirlenmiştir.

KRD BYM değişkenleri için yapılan standart granger nedensellik Test sonuçlarına göre(Tablo.2), krediden ekonomik büyümeye doğru nedensellik ilişkisinin bulunmadığını kabul eden sıfır hipotezi red edilmemiştir. Yani krediden ekonomik büyümeye doğru bir nedensellik ilişkisinin olmadığı sonucu çıkmıştır. Ancak büyümeden krediye doğru bir nedensellik ilişkisi bulunmaktadır. 
Uşak Üniversitesi Sosyal Bilimler Dergisi

$2013,6 / 3$

N. S. VURUR, E. ÖZEN

Tablo 2: VAR Granger Nedensellik Testi Sonuçları

\begin{tabular}{|c|c|c|}
\hline \multicolumn{3}{|l|}{ İnceleme dönemi: 1998:1-2012:1 } \\
\hline Gecikme Sayısı: 13 & F İstatistiği & Olasılık \\
\hline KRD BYM 'nin Granger nedeni değildir. & 1.31782 & 0.29233 \\
\hline BYM KRD'nın Granger nedeni değildir. & 3.87669 & 0.00518 \\
\hline \multicolumn{3}{|l|}{ Gecikme Sayısı:1 } \\
\hline MEV BYM' nin Granger nedeni değildir. & 6.34058 & 0.01486 \\
\hline BYM MEV' nin Granger nedeni değildir. & 1.35877 & 0.24897 \\
\hline \multicolumn{3}{|l|}{ Gecikme Sayısı: 5} \\
\hline KRD MEV' nin Granger nedeni değildir. & 0.28962 & 0.91602 \\
\hline MEV KRD' nin Granger nedeni değildir. & 5.96032 & 0.00031 \\
\hline
\end{tabular}

Optimal gecikme uzunluğu Akaike Bilgi Kriterine (AIC )e göre alınmıştır.

Büyüme ve mevduat değişkenlerine uygulanan Standart Granger Nedensellik testinde mevduat ile büyüme arasındaki nedensellik ilişkisinin bulunmadığını kabul eden sıfır hipotezi red edilmiştir. Ekonomik büyümeden mevduata doğru nedensellik ilişkisi bulunmazken, mevduattaki artışlar ile ekonomik büyüme arasında bir nedensellik ilişkisi bulunmuştur. Çalışmada kredi ile mevduat değişkenleri arasında nedensellik ilişkisinin bulunmadığını ifade eden sıfır hipotezi kabul edilmiştir. Banka kredisiyle banka mevduatları arasında nedensellik ilişkisi bulunmamasına karşılık, mevduatla kredi arasında bir nedensellik ilişkisi bulunmuştur Mevduatlarda görülen değişme krediler üzerinde de değişmeye neden olmaktadır.

\section{Sonuç}

Çalışmada ekonomik büyüme, kredi ve mevduat değişkenleri arasındaki nedensellik ilişkisi 1998:1-2012:1 dönemi üç aylık zaman serileri kullanılarak araştırılmıştır. Değişkenler arasındaki ilişkiler Granger nedensellik testi yardımıyla analiz edilmiştir. Elde edilen bulgulara göre; banka mevduatlarından ekonomik büyümeye, ekonomik büyümeden banka kredilerine ve banka mevduatlarından banka kredilerine doğru tek yönlü nedensellik ilişkisi söz konusudur. 
Literatürde ekonomik büyümenin mi finansal gelişmeyi arttırdığı yoksa finansal gelişmenin mi ekonomik büyümeyi arttırdığı konusunda iki farklı görüş bulunmaktadır. Ekonomik büyümenin finansal gelişmeyi arttırdığını ileri süren görüşler talep yönlü, finansal gelişmenin ekonomi büyümeyi arttırdığını öne süren görüşler ise arz yönlü görüşler olarak adlandırılmaktadır. Çalışmada elde edilen nedensellik ilişkisinin mevduattan ekonomik büyümeye doğru olduğu sonucu arz yönlü görüşleri destekler niteliktedir.

Çalışma sonuçlarına göre, GSMH'deki artışın mevduat hacmi üzerinde bir etkiye sahip olmaması; Türkiye'de güncelliğini koruyan bir tartışma konusu olan, tasarruf hacminin yetersiz olduğu tezini doğrular niteliğe sahiptir. Dünya bankası raporunda(2012), Türkiye'de son yıllarda açıklanan olumlu ekonomik büyüme göstergelerine rağmen tasarruf hacminin milli gelire oranının yeterince artmadığı, aksine azaldığ belirtilmektedir. Bu çalışmada banka mevduatları, büyümenin bir nedeni olarak bulunmuştur. Bu durumda düşük tasarruflara rağmen büyümenin nasıl sağlandığı, ya da ekonomik büyümeye rağmen, tasarrufların neden istenildiği gibi büyümediği sorgulanabilir. $\mathrm{Bu}$ sonuç, büyümenin diş kaynaklarla sağlandığını düşündürmektedir. Benzer gerekçe, Türkiye'de kredilerden ekonomik büyümeye doğru değil de, ekonomik büyümeden krediye doğru bir ilişki bulunması konusu için de kullanılabilir. Türkiye'deki güçlü tüketim eğilimi, düşük kur ile birleşince diş kaynak kullanımını cazip kılmakta, bu da cari açı artışını gündeme getirmektedir.

Çalışmada mevduatlardan krediye doğru bir nedensellik ilişkisinin bulunması, mevduat hacmindeki artışın kredi miktarını artmasına neden olduğunu göstermektedir. Kredi talebinin artması ise, mevduatlarda bir artışa neden olmamaktadır. Bu sonuç normal karşılanmalıdır. Çünkü mevduat tutarını kredi talebinin tek başına arttırması beklenmemelidir.

\section{Kaynakça}

Altıntaş H. ve Ayrıçay Y. (2010) “Türkiye'de Finansal Gelişme ve Ekonomik Büyüme İlişkisinin Sınır Testi Yaklaşımıyla Analizi:19872007", Anadolu Üniversitesi Sosyal Bilimler Dergisi, Cilt 10 Sayı 2, s. $71-98$

Alper, E. ve Öniş, Z. (2001) “Finansal Küreselleşme, Demokrasi Açı̆̆1 ve Yükselen Piyasalarda Yaşanan Sürekli Krizler: Sermaye 
Uşak Üniversitesi Sosyal Bilimler Dergisi

$2013,6 / 3$

N. S. VURUR, E. ÖZEN

Hareketlerinin Liberalleşmesi Sonrasında Türkiye Deneyimi", Doğu Batı Dergisi, 4(17), 203-225.

Al-Yousif, Y.K. (2002) "Financial Development and Economic Growth: Another Look at the Evidence from Developing Countries", Review of Financial Economics, 11(2), 131-150.

Arestis P., Panicos D., Luintel K.,(2001) "Financial Development and Economic Growth: The Role of Stock Markets", Journal of Money, Credit, and Banking, Vol.33, , ss.16- 41.

Artan S., (2007), "Finansal Kalkınmanın Büyümeye Etkileri: Literatür ve Uygulama", İktisat İşletme ve Finans, C.22, S.252, s.70-89

Aslan Ö. ve Küçükaksoy İ,.(2006) “Finansal Gelişme ve Ekonomik Büyüme İlişkisi: Türkiye Ekonomisi Üzerine Ekonometrik Bir Uygulama", İstanbul Üniversitesi İktisat Fakültesi Ekonometri ve İstatistik Dergisi, Sayı: 4, s.12-28.

Awokuse, T.O. (2003 )"Is the Export-Led Growth Hypothesis Valid For Canada? Canadian Journal of Economics, Cilt No: 36, Sayı: 1, , s.126-136

Beck, T.H.L. \& Demirgüç-Kunt, A. \& Laeven L. \& Levine, R.,( 2008). "Finance, firm size and growth," Open Access publications from Tilburg University urn:nbn:nl:ui:12-3132808, Tilburg University

Ceylan S., Durukaya M.,(2010)" Türkiye'de Kredi Kullanımı ve Ekonomik Büyüme İlişkisi", Atatürk Üniversitesi İktisadi İdari Bilimler Dergisi, Cilt:24, say1 2, s. 21-32

Chang P., Jia C., Wang Z. (2010) “ Bank fund reallocatioan and economic growth: evidence from China", Journal Of Banking\& Finance 34 , p.2753-2766

Demirgüç-Kunt, A. ve Maksimovic, V., (1998). Law, Finance, and Firm Growth. Journal of Finance 53, 2107-2137

Demirhan E., Aydemir O., İnkaya A., (2011)“The Direction Of Causality between Financial Devolopmentand Economic Growth: Evidence from Turkey", International Journal of Management Vol. 28., No1, p. 3-19 
Dişbudak C.,(2010) Analyzing the Bank Credit- Economic Growth Nexus in Turkey, European Journal Of Economics, Finace and Administrative Sciences ISSN 1450-2275 Issue 23

Dickey, D. A., Fuller, W. A.,(1981), "Likelihood Ratio Statistics for Autoregressive Time Series with a Unit Root", Econometrica, Cilt No: 49, Sayı: 4, s.1057-1072

Dünya Bankası, 2012, Yüksek Büyümenin Sürdürülebilirliği: Yurtiçi Tasarrufların Rolü, Türkiye Ülke Ekonomik Raporu, Türkiye Kalkınma Bakanlığı - Dünya Bankası, Rapor No: 66301-TR

Ersel H., Tarhan C., (2001) “Özel Ticari Bankaların Makroekonomik Ortamdaki değişikliklere Tepkileri", Mayıs-Haziran 2001, Active Dergisi

Granger CWJ (1988), "Some recent developments in the concept of causality". Journal of Econometrics 39:199-211.

Güven S, (2002), "Türkiye'de Banka Kredileri ve Büyüme İlişkisi", İktisat İşletme ve Finans, C.17, S.197, s.88-100

Islam M.A., Shah J.S.A.(2012), “An Empiricial Analysis of Causilty between Development of Non-Bank Financial Intermediaries and The Economic Growth in Malaysia"European Journal Of Social Sciences ISSN 1450-2267 Vol.30 No4, p 654-664

Kar M. ve Pentecost E.J. (2000) "Financial Development and Economic Growth in Turkey: Further Evidence on The Causality Issue", Loughborough University Economic Reserarch Paper, No:00/27, December, ss. 3-20.

Keskin, N. ve Karşıyakalı, B. (2006). “Finansal Kalkınma ve Ekonomik Büyüme İlişkisi:Koentegrasyon ve Nedensellik Analizi Bağlamında Türkiye Örneği", Türkiye Ekonomi KurumuUluslararası Ekonomi Konferansı, Ankara, Tebliğ Notları, 11-13 Eylül.

Levine, R., (1997). “Financial Development and Economic Growth: Views and Agenda" Journal of Economic Literature, 35, June, 687-726.

Levine, R., (2005). Finance and Growth: Theory and Evidence. Forthcoming in Philippe Aghion ve Steven Durlauf, eds. Handbook of Economic Growth. The Netherlands: Elsevier Science. 
Uşak Üniversitesi Sosyal Bilimler Dergisi

$2013,6 / 3$

N. S. VURUR, E. ÖZEN

Lu C.H., Shen C.H., "Banking Lendings and economic growth of Chinese Cities", China\&World and Economy Vol 20., No 2 p.59-79

Müslümov A., Aras G., (2002), Sermaye Piyasası Gelişmesi ve Ekonomik Büyüme Arasındaki Nedensellik İlişkisi: OECD Ülkeleri Örneği", İktisat İşletme ve Finans, C.17, S.198, s.90-100

Öztürk N., Darıcı H.K.,Kesikoğlu F.,(2011) “Ekonomik Büyüme ve Finansal Büyüme İlişkisi: Gelişmekte Olan Piyasalar için Panel Nedensellik Analizi", Marmara Üniversitesi İ.I.B.F. Dergisi, Cilt XXX, Sayı 1, s. 53-69

Rajan R., Zingales L., (1998), "Financial Dependence and Growth", American Economic Review 88, 559-587

Soytaş U., Küçükkaya E., (2011), “Economic Growth and Financial Development in Turkey: new Evidence", Applied Economics Letters, 18:6, 595-600

Şentürk S.H., (2005), “Ekonomik Büyümenin Sağlanmasında Finansal Sistemin Rolü", İktisat İşletme ve Finans, C.20, S.237, s.112-127

Xu Z.,, "Financial Development, Investment, and Growth", Economic Inquiry, Vol.38,ss.331- 344 .

Yılmaz Ö., Kaya V., (2006), "Finansal Kalkınma ve İktisadi Büyüme Arasındaki Nedensellik", İktisat İşletme ve Finans, C.21, S.244, s.120-131 